Int. J. Electrochem. Sci., 12 (2017) $629-638$

International Journal of

ELECTROCHEMICAL

SCIENCE

WWw.electrochemsci.org

\title{
Preparation of Graphene-Multi-Walled Carbon Nanotube Composite for Quantitive Determination of 2-hydroxy-3- Methylanthraquinone in Hedyotis diffusa
}

\author{
Zheng Wei ${ }^{l \#}$, Junping Zhang ${ }^{\text {I\# }}$, Xiaohe He ${ }^{2}$, Shufang $\mathrm{Ma}^{1}$, Aihua Zhang ${ }^{1}$, Weifeng Cui ${ }^{1}$, Yafeng Li $^{l}$, \\ Xiaoping Cai ${ }^{1}$, Shuibao Zhang ${ }^{2}$, Junming Fan ${ }^{1, *}$ \\ ${ }^{1}$ Henan Academy Institute of Traditional Chinese Medicine, Zhengzhou, 450000, Henan, P. R. China \\ ${ }^{2}$ Henan University of Chinese Medicine, Zhengzhou, 450000, Henan, P. R. China \\ \# These authors contributed equally to this work \\ *E-mail: junmingfan@yeah.net
}

doi: $10.20964 / 2017.01 .49$

Received: 20 October 2016 / Accepted: 15 November 2016 / Published: 12 December 2016

In this study, an electrochemical sensor based on a novel composite of reduced graphene oxide (GO) and multi-walled carbon nanotube (CNT) was developed for the detection of 2-hydroxy-3methylanthraquinone. First, GO was employed to disperse CNT as a dispersant. Then GO was reduced electrochemically into RGO after being deposited on the surface of ITO. Thus, the designed electrochemical sensor based on RGO/CNT/ITO for detecting 2-hydroxy-3-methylanthraquinone was first reported. Cyclic voltammetry and electrochemical impedance spectroscopy (EIS) were employed to analyse the sensor. The results indicated that the sensor exhibited an electrocatalytic activity for the reduction of 2-hydroxy-3-methylanthraquinone. In particular, the electrochemical reduction of 2hydroxy-3-methylanthraquinone was remarkably enhanced by the RGO/CNT composite. Besides, the sensor was efficient in determining 2-hydroxy-3-methylanthraquinone in Hedyotis diffusa, where the sensor exhibited a linear response range from 2 to $600 \mu \mathrm{M}$.

Keywords: Graphene; Carbon nanotube; Sensor; Electrocatalysis; Hedyotis diffusa

\section{FULL TEXT}

(C) 2017 The Authors. Published by ESG (www.electrochemsci.org). This article is an open access article distributed under the terms and conditions of the Creative Commons Attribution license (http://creativecommons.org/licenses/by/4.0/). 